\title{
Análise da reatividade de folhelhos do Recôncavo Baiano
}

\section{(Reactive analysis of shales from Recôncavo Baiano)}

\author{
D. V. Lucena', L. V. Amorim ${ }^{2}$, H. L. Lira ${ }^{3}$ \\ ${ }^{I}$ Departamento de Petróleo e Gás, Instituto Federal de Educação, Ciência e Tecnologia da Paraíba, Campus \\ Campina Grande, Rua Tranquilino Coelho Lemos, 671, Dinamérica, Campina Grande, PB 58432-300 \\ ${ }^{2}$ Unidade Acadêmica de Engenharia Mecânica, ${ }^{3}$ Unidade Acadêmica de Engenharia de Materiais \\ Universidade Federal de Campina Grande, R. Aprígio Veloso, 882, bairro Universitário, \\ Campina Grande, PB 58109-900 \\ danielly.lucena@ifpb.edu.br,lvamorim@gmail.com,hélio.lucena@dema.ufcg.edu.br
}

\begin{abstract}
Resumo
O problema da estabilidade do poço em formações expansivas frustrou os engenheiros de campos de petróleo desde o início da exploração de petróleo e gás natural. A estabilidade de folhelhos ricos em argila é profundamente afetada por suas interações físicas e químicas complexas com fluidos de perfuração. Assim, estas rochas com alto teor de argila mostraram alterações significativas, tais como inchaço ou expansão, quando colocadas em contato com fluidos aquosos para a adsorção de moléculas polares de água ou íons hidratados dissolvidos no meio. Essas mudanças podem causar colapso da rocha durante a perfuração com fluidos de perfuração à base de água. Para uma melhor compreensão dos fenômenos de interação entre a rocha e o fluido de perfuração, este trabalho objetiva a análise da reatividade de folhelhos provenientes do Recôncavo Baiano por meio da sua caracterização. Para isto, os folhelhos foram submetidos a ensaios de CTC, FRX, DRX e inchamento de Foster. Foi possível detectar que os folhelhos apresentaram significativos valores de CTC, bem como FRX com composição próxima da esmectita e padrão de DRX com picos característicos da esmectita. Em relação ao inchamento de Foster, o folhelho com maior CTC também apresentou o maior valor de inchamento indicando que a CTC pode ser aplicada como parâmetro indicativo da reatividade.

Palavras-chave: formações reativas, caracterização, fluidos de perfuração inibidos.
\end{abstract}

\begin{abstract}
The problem of wellbore stability in expansive formations has frustrated engineers of oil fields since the start of oil and gas well perforation. The stability of shales rich in clay are deeply affected by its complex physical and chemical interactions with drilling fluids. Thus, these rocks with a high content of clay have shown significant changes, such as swelling or expanding, when placed in contact with aqueous fluids due to the adsorption of polar molecules of water or hydrated ions dissolved in the medium. These changes may cause collapse of the rock during drilling with water-based drilling fluids. For a better understanding of the phenomenon of interaction between the rock and the drilling fluid, this study aims to analyze reactivity of shales from the Recôncavo Baiano through their characterization. For this, the shales were characterized by CEC, XRF, XRD and Foster swelling. The results indicated that the shales showed significant values of CEC, FRX composition close to that of smectite, and XRD pattern with characteristic peaks of smectite. Regarding to Foster swelling, the shale of higher CEC also presented the higher value of swelling, indicating that the CEC can be applied as a parameter indicative of the reactivity.
\end{abstract}

Keywords: reactive formation, characterization, inhibited drilling fluids.

\section{INTRODUÇÃO}

Os problemas de estabilidade de poços, relacionados com o aumento do número de cenários de perfuração envolvendo reservatórios, nos quais é comum a presença de formações geológicas de difícil perfuração, a exemplo de folhelhos reativos, configuram-se como uma das principais dificuldades encontradas na operação de perfuração de poços de petróleo [1-6]. Para Fontoura [7], os folhelhos são, entre as rochas sedimentares, as mais finamente laminadas e apresentam distintas camadas estratificadas de moderado a alto teor de argila, e concluiu que devido a essas características os folhelhos são suscetíveis a diferentes fenômenos que causam instabilidade no processo de perfuração de poços de petróleo e gás. Segundo [8], a composição dos folhelhos pode variar de acordo com a pré-disposição da rocha fonte, controlando a coloração, que varia do vermelho amarronzado ao preto. Para [9], os folhelhos normalmente derivam de dois tipos de ambientes: marinhos (ricos em clorita e argilas do grupo da ilita) ou lacustres (enriquecidos com esmectita). Al-Bazali et al. [10] citam que os folhelhos têm um papel importante na exploração e produção de petróleo, pois são comumente encontrados como rochas geradoras. Cygan et al. [11] associam as características dos folhelhos, como a resistência, 
tendência à hidratação e a dispersão, com a fração de argila e o tipo de argilomineral, ou seja, folhelhos mais hidratáveis e mais facilmente dispersáveis provavelmente apresentam em sua composição mineralógica teores consideráveis de argila reativa. Segundo os autores, através da caracterização dos minerais que os compõem é possível conhecer o potencial de instabilidade dos folhelhos frente à perfuração.

Observa-se que as características distintivas de folhelhos estão relacionadas com seu conteúdo de argila e sua baixa conectividade dos poros. Essas características os tornam suscetíveis a fenômenos como a hidratação e inchamento diminuindo, assim, a estabilidade do poço [12]. Para Fontoura [7], os folhelhos, em relação à indústria do petróleo, são rochas sedimentares detríticas formadas pelo adensamento e compactação de sedimentos de granulometria fina (argilas e siltes), onde a sua fração argila pode variar entre $15 \%$ até próximo a $100 \%$. Para [13], a estabilidade de folhelhos ricos em argila é profundamente afetada por suas complexas interações físicas e químicas com fluidos de perfuração. Deste modo, essas rochas com alto teor de argila têm mostrado significativas alterações, tais como expansão ou inchamento, quando colocadas em contato com fluidos aquosos devido à adsorção de moléculas polares de água ou de íons hidratados solubilizados no meio. Essas alterações podem provocar o colapso da rocha durante a perfuração com fluidos à base de água [8]. Como estes argilominerais possuem diferentes energias de hidratação, a capacidade de certo folhelho adsorver água é função dos tipos e quantidades dos argilominerais que o compõe [7]. O movimento de água no interior dos folhelhos ocorre em função do gradiente de atividade química existente entre os fluidos de perfuração e os folhelhos, devido à pressão osmótica. A atividade química define a salinidade de um fluido de perfuração, sendo assim, um fluido de perfuração que possui alta atividade apresenta baixa salinidade, fazendo assim com que ocorra fluxo de água para dentro da formação. Deste modo, a presença de sais (inibidores de expansão) no fluido de perfuração é indispensável para a manutenção da estabilidade de formações reativas [14]. Pesquisas realizadas mostraram que as interações entre folhelho e fluido de perfuração podem ser reguladas para aumentar e melhorar a estabilização do poço; além disso, os resultados indicam que os melhores desempenhos foram apresentados pelos inibidores com íons $\mathrm{K}^{+}[15]$.

Vários estudos concluíram que a utilização de técnicas como a difração de raios $\mathrm{X}$ e a capacidade de troca de cátions constituem-se em importantes ferramentas para explicar o controle de inchamento promovido pelos inibidores [16]. Estudar formações geológicas suscetíveis à hidratação configura-se como um desafio por se tratar de um fenômeno responsável por cerca de $90 \%$ dos problemas relacionados com a perfuração de poços de petróleo, além de se tratar de um tema que pouco se conhece sobre os mecanismos que regem tal fenômeno e, ainda, pela escassa variedade de estudos voltados para a análise de diferentes produtos que evitem a ocorrência da problemática (inibidores) da hidratação. Para um maior entendimento dos fenômenos de interação entre a rocha e o fluido de perfuração é necessário, primeiramente, que se tenha uma descrição completa destas formações ativas, tanto do ponto de vista de seus constituintes individuais quanto da sua microestrutura [17]. A caracterização de todas as amostras juntamente com a realização do ensaio de inchamento de Foster tem a finalidade de identificar a suscetibilidade dos folhelhos à hidratação. As informações obtidas a partir da realização destes ensaios aplicam-se para a realização segura da atividade de perfuração de poços de petróleo, pois folhelhos reativos requerem fluidos de perfuração aditivados adequadamente para que problemas como o aprisionamento da coluna de perfuração e o encerramento da broca sejam evitados durante o prosseguimento da operação de perfuração. Portanto, o objetivo deste trabalho é realizar uma caracterização completa das amostras de argila e folhelhos do Recôncavo Baiano para melhor entendimento do fenômeno de hidratação que ocorre nesse tipo de formação e as interações das mesmas com o fluido de perfuração.

\section{EXPERIMENTAL}

Materiais: foram estudadas uma amostra de argila bentonítica industrializada Brasgel PA (Bentonit União Nordeste Ltda. - BUN) e amostras de folhelhos do Recôncavo Baiano de duas formações, uma da Formação Candeias (F1) e outra da Formação São Sebastião (F2).

Capacidade de troca de cátions (CTC): a CTC da argila foi determinada a partir do método de adsorção de azul de metileno [18]. O princípio do ensaio consiste em introduzir quantidades crescentes de solução de azul de metileno, por doses sucessivas, até que a superfície das partículas, que têm capacidade de adsorção, esteja coberta. De acordo com [19], o teor de esmectita de uma formação reativa a ser perfurada apresenta-se em muitas ocasiões como o único parâmetro para escolha adequada de um fluido de perfuração, devido ao alto potencial de expansibilidade que este argilomineral apresenta (que pode ser constatado pela faixa de CTC apresentada).

Fluorescência de raios $X(F R X)$ : a análise química das argilas por FRX foi realizada pelo método semiquantitativo, sob atmosfera de nitrogênio. O material fornecido foi quarteado e prensado em prensa manual em forma de pastilha, com diâmetro de aproximadamente $15 \mathrm{~mm}$. O equipamento utilizado foi EDX-720 da Shimadzu.

Difração de raios $X(D R X)$ : para identificação de constituintes mineralógicos das amostras por meio de um estudo qualitativo foi utilizada a técnica de DRX. As análises das amostras, na forma seca e tratadas com etileno glicol, foram realizadas em difratômetro de raios X da Shimadzu, XRD-6000, operando com radiação K- $\alpha$ de cobre, com voltagem de $40 \mathrm{kV}$ e $30 \mathrm{~mA}$ de corrente e comprimento de onda $\lambda=1,5406 \AA$. As amostras foram analisadas com varredura entre $2 \theta$ de $3^{\circ}$ e $70^{\circ}$; a velocidade do goniômetro foi $2 \% \mathrm{~min}$.

Ensaio de inchamento de Foster: com o objetivo de selecionar as concentrações dos inibidores que apresentem 
os melhores resultados em relação ao seu desempenho e de avaliar o grau de inibição de argilas expansivas dos inibidores químicos, foram realizados ensaios de inchamento de Foster [20]. Para tanto, em uma proveta de $100 \mathrm{~mL}$ contendo 50 $\mathrm{mL}$ de água e inibidores em concentrações definidas $(16,18$ e $20 \mathrm{~g}$ de inibidor $/ 350 \mathrm{~mL}$ de água), foram adicionados lentamente $1 \mathrm{~g}$ de argila bentonítica ativada. Os sistemas foram deixados em repouso e após $24 \mathrm{~h}$ foram efetuadas as leituras do inchamento a partir do volume do recipiente.

\section{RESULTADOS E DISCUSSÃO}

Acaracterização dos folhelhos tem como objetivo auxiliar na previsão de instabilidades geradas pelas interações entre os fluidos de perfuração e as amostras de estudo, que podem ocorrer quando operações de perfuração de poços de petróleo atravessam esse tipo de formação. A caracterização das amostras estudadas (folhelhos e argilas) foi realizada por meio da capacidade de troca de cátions, análise química (fluorescência de raios X) e difração de raios X. As Tabelas I e II apresentam, respectivamente, os valores típicos de CTC de alguns argilominerais e os valores da CTC obtidos para as amostras estudadas. É possível fazer uma correlação entre o valor da CTC das amostras estudadas com o potencial de reatividade de acordo com a análise da Tabela I, pois se observa que os valores de CTC obtidos para as amostras estudadas apresentaram-se próximos à faixa estabelecida por [19] para a esmectita, ou seja, há um indicativo que essas amostras apresentam conteúdo considerável de esmectita em sua composição de acordo com este parâmetro. Rabe e Fontoura [17] apontam que folhelhos que possuem CTC entre 47 e 49 meq/100 g são classificados como folhelhos com elevados valores de troca catiônica, indicando assim certa reatividade das amostras.

Pode-se observar na Tabela II, que as amostras F1, F2

Tabela I - Valores característicos da CTC de argilominerais importantes [19].

[Table I - Characteristic values of CEC of important clay minerals [19].]

\begin{tabular}{cc}
\hline Argilomineral & CTC $(\mathrm{meq} / 100 \mathrm{~g})$ \\
\hline Caulinita & $3-15$ \\
Ilita & $10-40$ \\
Esmectita & $80-150$ \\
\hline
\end{tabular}

Tabela II - Capacidade de troca de cátions (CTC) para as amostras reativas estudadas.

[Table II - Cation exchange capacity (CEC) for reactive samples studied.]

\begin{tabular}{cc}
\hline Amostra & CTC $(\mathrm{meq} / 100 \mathrm{~g})$ \\
\hline F1 & 72 \\
F2 & 66 \\
Brasgel PA & 84 \\
\hline
\end{tabular}

e Brasgel PA (72, 66 e $84 \mathrm{meq} / 100 \mathrm{~g}$, respectivamente) possuem significativos valores de capacidades de troca de cátions, ou seja, apresentam probabilidade de maior capacidade de absorver água e consequentemente maiores taxas de expansão. Pelo exposto pode-se afirmar que a amostra de Brasgel PA apresenta-se com CTC dentro da faixa estabelecida para a esmectita $(80$ a $100 \mathrm{meq} / 100$ g), indicando que provavelmente a amostra apresentese composta essencialmente por este argilomineral, o que explica a maior tendência que essa amostra possui em relação à hidratação. Sabe-se que as formações reativas, quando em suspensão aquosa, fixam por adsorção uma quantidade considerável de líquido por apresentarem dentro de sua estrutura cristalográfica elevado grau de substituição isomórfica, o que origina um excesso de carga negativa que são compensadas por cátions interlamelares ocasionando aumento aparente do próprio volume e aumentando a distância interplanar basal das camadas da argila. Assim, os altos valores de CTC obtidos para os folhelhos analisados indicam a grande facilidade dos mesmos trocarem cátions e adsorverem água, o que resulta no fenômeno conhecido como inchamento ou expansão. A magnitude deste fenômeno depende da natureza dos cátions trocáveis e da estrutura do meio circundante. Deste modo, o conhecimento desta propriedade relativa à formação geológica é de grande importância para que se possibilite o controle de tal propriedade com o uso da formulação do fluido de perfuração adequado para formações que apresentam alta reatividade, devido à relação existente entre altos valores de CTC e reatividade.

$\mathrm{Na}$ Tabela III estão apresentados os resultados das composições químicas obtidas para os folhelhos listados na Tabela II a partir da técnica de fluorescência de raios X (FRX). Os difratogramas das amostras estudadas podem ser observados nas Figs. 1 a 3. Os ensaios de difração de raios $\mathrm{X}$ foram realizados com as amostras sem a presença e com a presença de etileno glicol. Para este último, as amostras apresentam a sigla EG após sua nomenclatura normal. A simbologia existente nos gráficos é referente aos seguintes minerais: E - grupo da esmectita; I - ilita; C - caulinita; Q quartzo; D - dolomita.

A partir da análise da Tabela III, verifica-se que todos os folhelhos estudados apresentaram alta proporção de silicatos e aluminatos, o que provavelmente indica a existência de quartzo $\left(\mathrm{SiO}_{2}\right)$ e de argilominerais como a caulinita, esmectita e ilita em suas composições. Segundo [21], um aspecto importante com relação à composição química é a elevada quantidade de alguns óxidos $\left(\mathrm{Fe}_{2} \mathrm{O}_{3}, \mathrm{Na}_{2} \mathrm{O}, \mathrm{K}_{2} \mathrm{O}\right.$, $\mathrm{CaO}$ e $\mathrm{MgO}$ ) presentes em algumas amostras (amostras F1 e F2, por exemplo); comparando o resultado desse somatório percentual com a mineralogia, indica-se que o mesmo está associado à presença de argilas com ocorrência de esmectita. Observa-se por meio dos resultados obtidos através da análise química que há fortes indícios da existência da argila esmectita nos folhelhos analisados. Sabe-se que as esmectitas aparecem frequentemente como componente de formações expansíveis e sua presença causa entumecimento 
Tabela III - Composição percentual (\% em massa) obtida a partir das análises químicas dos constituintes dos folhelhos. [Table III - Percentage composition (wt\%) obtained from the chemical analysis of the constituents of the shale.]

\begin{tabular}{ccccccccccccc}
\hline Amostra & $\mathrm{SiO}_{2}$ & $\mathrm{Al}_{2} \mathrm{O}_{3}$ & $\mathrm{Fe}_{2} \mathrm{O}_{3}$ & $\mathrm{~K}_{2} \mathrm{O}$ & $\mathrm{MgO}$ & $\mathrm{TiO}_{2}$ & $\mathrm{MnO}$ & $\mathrm{BaO}$ & $\mathrm{SO}_{3}$ & $\mathrm{P}_{2} \mathrm{O}_{5}$ & $\mathrm{CaO}$ & $\mathrm{Na}_{2} \mathrm{O}$ \\
\hline $\mathrm{F} 1$ & 57,33 & 21,25 & 8,71 & 5,61 & 3,98 & 1,03 & 0,38 & 0,30 & 0,21 & 0,07 & - & 0,85 \\
F2 & 53,46 & 17,00 & 8,65 & 3,94 & 5,15 & 0,72 & 0,13 & 0,34 & 0,28 & 0,05 & 9,27 & 0,71 \\
Brasgel PA & 64,11 & 18,53 & 9,39 & 0,44 & 2,66 & 0,88 & 0,04 & 0,23 & 0,28 & 0,26 & 1,27 & 1,84 \\
\hline
\end{tabular}
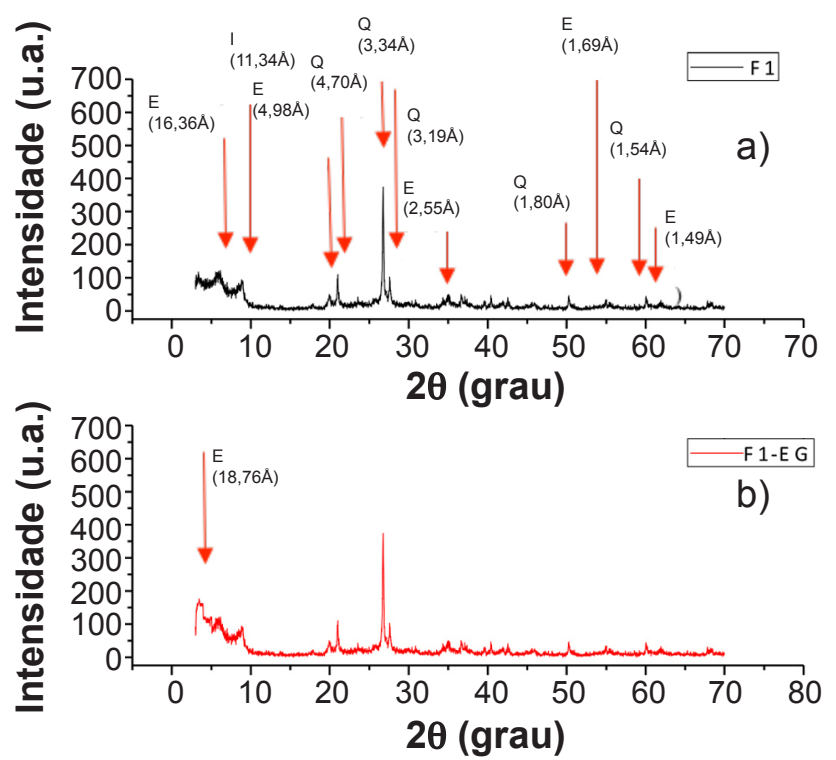

Figura 1: Difratogramas de raios $\mathrm{X}$ para a amostra de folhelho $\mathrm{F}$ 1 com e sem etileno glicol.

[Figure 1: X-ray diffraction patterns for the F1 shale sample with and without ethylene glycol.]

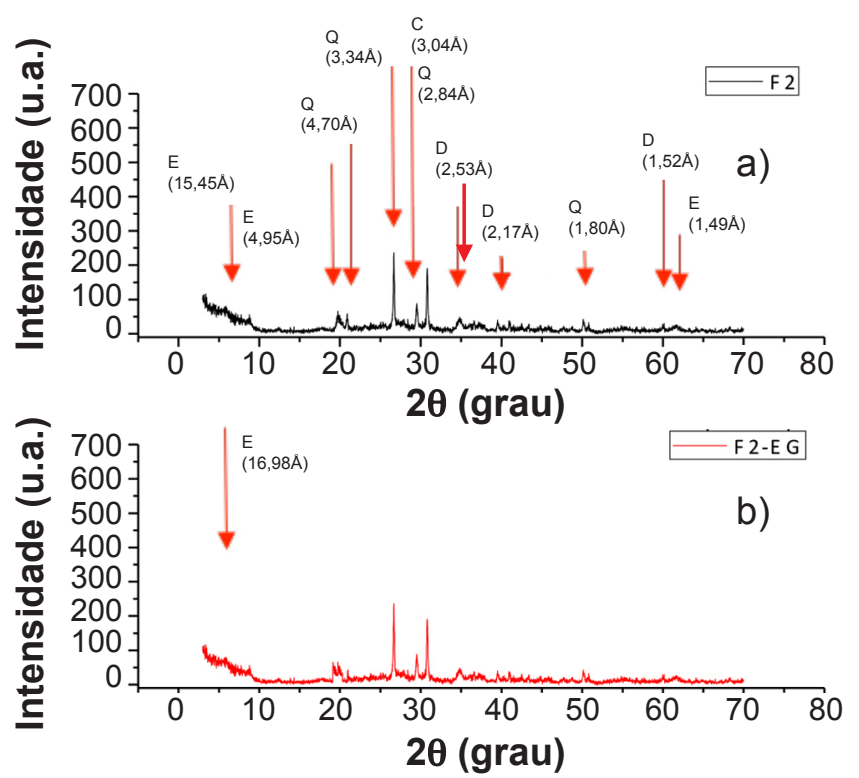

Figura 2: Difratogramas de raios $\mathrm{X}$ para a amostra de folhelho F2 com e sem etileno glicol.

[Figure 2: X-ray diffraction patterns for the F2 shale sample with and without ethylene glycol.]

dos folhelhos quando colocado em contato com água. Esse comportamento advém do fato de suas camadas serem
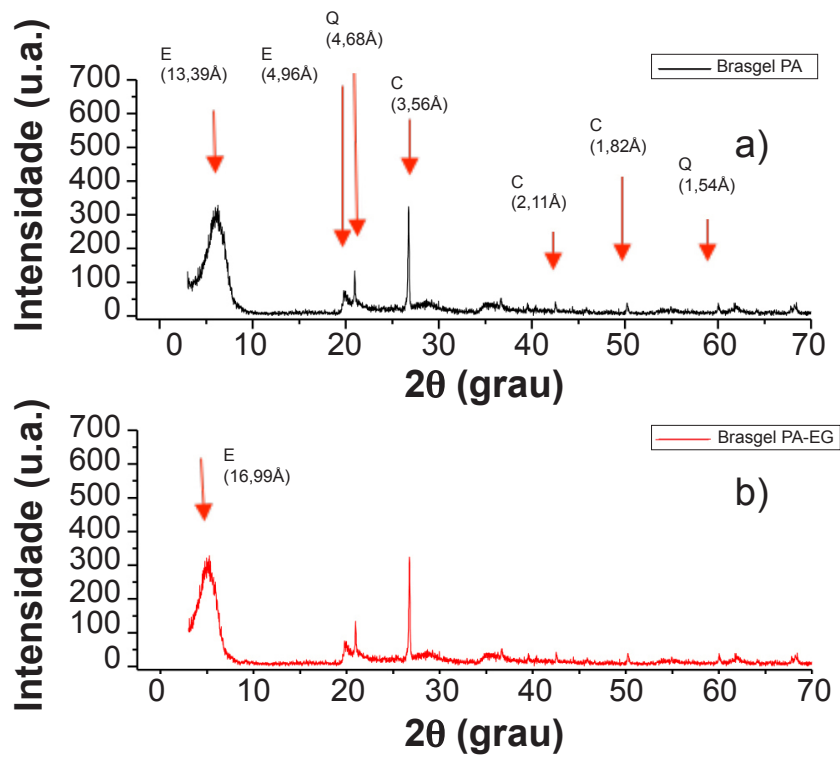

Figura 3: Difratogramas de raios $\mathrm{X}$ para a amostra de argila Brasgel PA com e sem etileno glicol.

[Figure 3: X-ray diffraction patterns for the sample of clay Brasgel $P A$ with and without ethylene glycol.]

facilmente separáveis pela água adsorvida devido às suas camadas negativas. O F1 apresenta cerca de $57 \%$ de $\mathrm{SiO}_{2}$ que aponta presença de quartzo na sua composição, como pode ser comprovada por meio do difratograma da Fig. 1. A presença de $\mathrm{Al}_{2} \mathrm{O}_{3}$ também se mostra significativa $(21,25 \%)$, o que indica que a amostra se trata de um folhelho comum. A presença de $\mathrm{SiO}_{2}$ com o $\mathrm{Al}_{2} \mathrm{O}_{3}$ indica argilominerais como a caulinita, esmectita e ilita, que pode explicar a reatividade constatada a partir do CTC da amostra. O teor de $8,71 \%$ de $\mathrm{Fe}_{2} \mathrm{O}_{3}$ assinala a presença de argilomineral do tipo esmectita, assim como também evidencia a presença de ilita; o teor de $5,61 \%$ de $\mathrm{K}_{2} \mathrm{O}$ também está relacionado à presença de ilita. Ainda no difratograma da Fig. 1 do folhelho F1, pode-se observar picos referentes à esmectita (com deslocamento para a direita da reflexāo do pico de $1^{\mathrm{a}}$ ordem $\left(\mathrm{d}_{001}\right)$ de 16,36 para $18,76 \AA$ A), a presença de ilita, além da presença de quartzo na amostra analisada. O deslocamento do pico para as amostras tratadas com etileno glicol indica presença de esmectita na composição das amostras, pois o deslocamento do pico entre 15 e $19 \AA$ caracteriza que uma amostra possui argilomineral do tipo esmectítico.

Ao realizar-se a análise da amostra F2 (Fig. 2), observase que assim como o folhelho F1 o mesmo apresenta um alto teor de $\mathrm{SiO}_{2}(53,46 \%)$; visualiza-se também uma presença 
considerável de $\mathrm{Al}_{2} \mathrm{O}_{3}(18,00 \%)$, valor que se aproxima bastante do obtido por [19], ou seja, está relacionada à presença de esmectita na amostra. Por meio da Fig. 2 detecta-se pico característico da presença de argilomineral do grupo da esmectita na amostra F2. Observam-se picos referentes à dolomita a 2,53,2,17 e 1,52 A (os altos teores dos óxidos de magnésio e cálcio indicados pela análise de composição química podem ser explicados pela presença de dolomita indicada por DRX). Observa-se também presença do quartzo. A amostra Brasgel PA (Fig. 3) apresenta altos teores de $\mathrm{SiO}_{2}(64,11 \%)$ e de $\mathrm{Al}_{2} \mathrm{O}_{3}(18,53 \%)$, sendo estes um indicativo de presença de argilominerais como a esmectita, assim como o alto teor de $\mathrm{Fe}_{2} \mathrm{O}_{3}(9,39 \%)$ também aponta a presença de argilominerais do grupo da esmectita. Os argilominerais detectados por DRX na amostra Brasgel PA confirmam os resultados obtidos por meio da análise da FRX. No difratograma da Fig. 3 referente à análise da amostra de argila Brasgel PA, observa-se o deslocamento de pico característico da esmectita. Além da esmectita, também se observam os picos referentes à presença do quartzo. Estudos realizados por [22] identificaram fases mineralógicas (esmectita, caulinita e quartzo) compatíveis com as observadas no difratograma da amostra da argila Brasgel PA (Fig. 3), indicando que a amostra de Brasgel PA apresenta difratograma típico de uma argila bentonítica.

Observa-se por meio dos resultados obtidos através da análise química que há fortes indícios da existência da argila esmectita nos folhelhos analisados. A confirmação da presença do argilomineral esmectítico nos folhelhos foi confirmada através dos resultados do ensaio de DRX. Na análise e estudo de folhelhos o teor de esmectita presente nos mesmos é, muitas vezes, a única propriedade da formação estudada para definir o tipo de fluido de perfuração escolhido, em função do alto potencial de expansibilidade desses argilominerais com o seu potencial de reatividade. Desta forma, a detecção da presença das esmectitas é de grande importância para explicar os fenômenos relativos à hidratação de formações que as contêm em grande proporção. Fazendo-se a análise conjunta dos resultados obtidos por meio dos ensaios de caracterização dos folhelhos, podese constatar a partir dos ensaios de caracterização que as amostras analisadas apresentaram-se com propensão para reatividade de tais amostras, pois as mesmas apresentaram indicativos da presença de argilominerais reativos em presença de água em suas composições. De acordo com [23], que também abordou a correlação de reatividade e caracterização de folhelhos e argilas, as formações que apresentaram picos característicos da esmectita apresentamse com maior probabilidade de expansão frente à água, corroborando assim os resultados obtidos e discutidos para as amostras do presente estudo. A estabilidade de folhelhos ricos em argila é profundamente afetada por suas complexas interações físicas e químicas com fluidos de perfuração. Deste modo, essas rochas com alto teor de argila têm mostrado significativas alterações, tais como expansão ou inchamento, quando colocadas em contato com soluções aquosas devido à sua grande adsorção de moléculas polares de água ou de íons hidratados solubilizados no meio, podendo provocar o colapso da rocha durante a perfuração com fluidos à base de água; assim, faz-se necessária a análise da interação das formações reativas na presença de soluções aquosas, como se pode obter a partir da realização do ensaio de inchamento de Foster.

Nas Figs. 4, 5 e 6 estão apresentados os resultados dos ensaios de inchamento de Foster dos inibidores sulfato de potássio, acetato de potássio, citrato de potássio e cloreto de potássio $(\mathrm{KCl})$ isoladamente, para três diferentes concentrações (16, 18 e $20 \mathrm{~g} / 350 \mathrm{~mL}$ de água) na presença dos folhelhos F1 e F2 e para a argila Brasgel PA, respectivamente. A adição de inibidores se dá com o objetivo de prevenir a hidratação de argilas, que atuam basicamente a partir da fixação de sua fração catiônica na superfície negativa das partículas de argila. $\mathrm{O}$ ensaio de inchamento

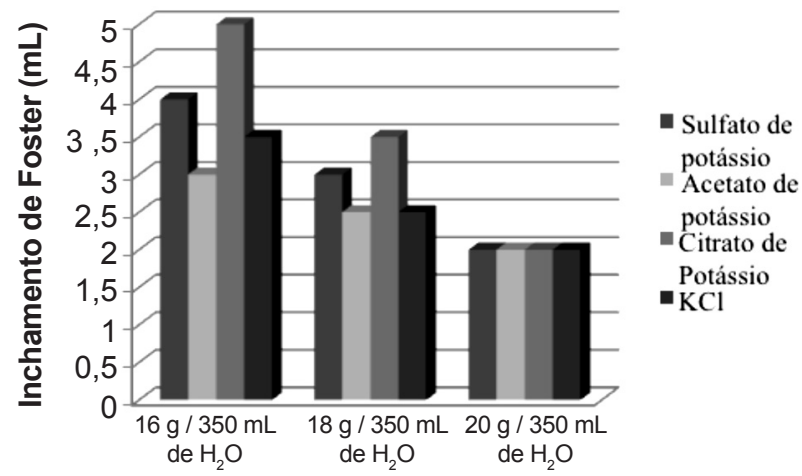

Figura 4: Inchamento de Foster aplicado à amostra F1 para os inibidores sulfato de potássio, acetato de potássio, citrato de potássio e cloreto de potássio para as concentrações de 16, 18 e $20 \mathrm{~g}$ de inibidor $/ 350 \mathrm{~mL}$ de água.

[Figure 4: Foster swelling applied to the sample F1 for inhibitors of potassium sulfate, potassium acetate, potassium citrate and potassium chloride in concentrations of 16,18 and $20 \mathrm{~g}$ of the inhibitor / $350 \mathrm{~mL}$ water.]

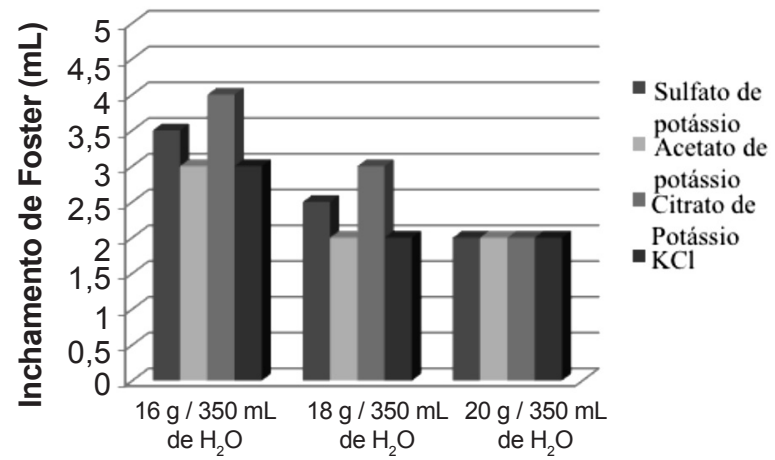

Figura 5: Inchamento de Foster aplicado à amostra F2 para os inibidores sulfato de potássio, acetato de potássio, citrato de potássio e cloreto de potássio para as concentrações de 16,18 e $20 \mathrm{~g}$ de inibidor/ $350 \mathrm{~mL}$ de água.

[Figure 5: Foster swelling applied to the sample F2 for inhibitors of potassium sulfate, potassium acetate, potassium citrate and potassium chloride in concentrations of 16,18 and $20 \mathrm{~g}$ of the inhibitor / $350 \mathrm{~mL}$ water.] 


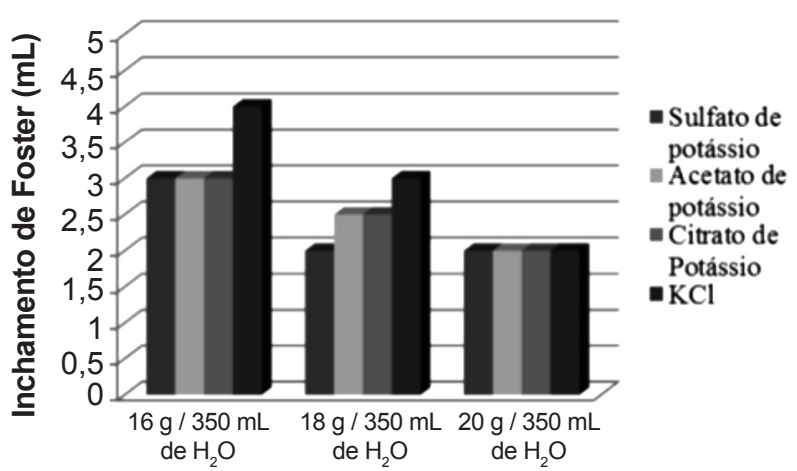

Figura 6: Inchamento de Foster aplicado à argila Brasgel PA para os inibidores sulfato de potássio, acetato de potássio, citrato de potássio e cloreto de potássio para as concentrações de 16,18 e $20 \mathrm{~g}$ de inibidor/ $350 \mathrm{~mL}$ de água.

[Figure 6: Foster swelling applied to Brasgel PA clay for inhibitors of potassium sulfate, potassium acetate, potassium citrate and potassium chloride in concentrations of 16,18 and $20 \mathrm{~g}$ of the inhibitor / $350 \mathrm{~mL}$ water.]

de Foster mostra a interação dos folhelhos com o fluido de perfuração, assim como ocorre durante a operação de perfuração. De acordo com a classificação de Foster [20], valores iguais ou menores que $2 \mathrm{~mL}$ correspondem a um inchamento nulo, valores entre 3 e $5 \mathrm{~mL}$ correspondem a um inchamento baixo, valores entre 6 e $8 \mathrm{~mL}$ correspondem a um inchamento médio e para valores superiores a $8 \mathrm{~mL}$ o grau de inchamento da argila é classificado como alto.

A partir da Fig. 4 pode-se constatar que o inchamento nulo foi obtido apenas para a concentração de $20 \mathrm{~g} / 350 \mathrm{~mL}$ de água para todos os inibidores ensaiados. Já a amostra F2 (Fig. 5) apresentou valores de inchamento nulo de acordo com a classificação de Foster a partir da concentração de 18 g/ 350 $\mathrm{mL}$ de água (para os inibidores acetato de potássio e $\mathrm{KCl}$ ); este resultado pode estar relacionado ao fato desta amostra ter apresentado o menor valor de CTC dentre as três amostras estudadas, pois o valor mais baixo da CTC relaciona-se com a menor reatividade da amostra F2 e consequente obtenção de nulidade de inchamento em concentração inferior ao da amostra F1. Analisando a Fig. 6, pode-se constatar a partir dos ensaios que para a concentração de $18 \mathrm{~g} / 350 \mathrm{~mL}$ de água o sulfato de potássio já apresenta valor nulo de inchamento, comprovando a efetiva inibição a partir desta concentração. Observa-se também que na concentração de $20 \mathrm{~g} / 350 \mathrm{~mL}$ todos os inibidores analisados apresentaram inchamento nulo de acordo com a classificação estabelecida pelo ensaio. Para o ensaio em água (sem presença de inibidor), a Brasgel PA apresentou um inchamento de $17 \mathrm{~mL}$. Indica-se assim que todos os inibidores foram efetivos em relação à inibição de inchamento, pois os mesmos promoveram redução nos valores do inchamento. A partir do exposto e da análise do resultado do ensaio, pode-se indicar que a concentração de $20 \mathrm{~g}$ de inibidor / $350 \mathrm{~mL}$ de água como componente da solução garante uma diferença de concentração suficiente para evitar a invasão da água do fluido para as formações, o que explica a nulidade de inchamento para tal concentração para todos os inibidores estudados.
Pode-se indicar que a partir das informações obtidas por meio da caracterização realizada para os folhelhos que esmectitas aparecem frequentemente como componente de formações expansíveis. Os ensaios de inchamento de Foster apresentaram resultados que corroboram o que foi obtido na caracterização das amostras estudadas, pois os ensaios realizados com soluções sem a presença de inibidor indicaram altos valores de inchamento. Esse fato é explicado pela estrutura das esmectitas, pois as mesmas possuem caráter bipolar, com cargas negativas localizadas no plano de maior dimensão (face) e cargas positivas na região de menor dimensão (aresta). Assim, sua presença causa entumecimento dos folhelhos quando colocado em contato com água e esse comportamento advém do fato de suas camadas serem facilmente separáveis pela água adsorvida devido às suas camadas negativas. A necessidade de um aumento na concentração de inibidor para um efetivo controle da expansão pode estar relacionada à sua atividade química. Sendo assim, para que o fluido de perfuração apresente uma atividade menor que a da formação, faz-se necessário que o mesmo apresente certa concentração de sal, para que assim o fluxo de água ocorra da formação para o fluido de perfuração, evitando assim a expansão.

$\mathrm{Na}$ análise conjunta dos resultados obtidos para o controle de hidratação dos folhelhos e da argila Brasgel PA, pode-se observar que em ambos os casos o inibidor citrato de potássio apresentou um aumento significativo na sua capacidade de controle de hidratação com o aumento da concentração do inibidor; deste modo, este inibidor apresentou uma capacidade bastante acentuada na redução da expansão com o aumento progressivo da concentração. A alta capacidade de controle de hidratação deste inibidor pode ser proveniente da inibição física promovida pelo contraíon, que apresenta três sítios ativos aniônicos e promove um aumento da inibição física (a partir da união das arestas da argila) com o aumento da concentração. Além disso, todos os inibidores foram efetivos no controle do inchamento quando comparados aos ensaios realizados sem a presença destes aditivos. A partir dos resultados obtidos com a aplicação da metodologia de Foster para as soluções compostas com os inibidores isoladamente, pode-se indicar que a concentração que apresentou resultados mais positivos para preparação dos fluidos de perfuração foi de $20 \mathrm{~g}$ de inibidor / $350 \mathrm{~mL}$ de água, já que para esta concentração todos os inibidores estudados apresentaram inchamento nulo.

\section{CONCLUSÕES}

Os folhelhos que apresentaram esmectita em sua composição, de acordo com os ensaios de FRX e DRX, apresentaram reatividade semelhante ao apresentado pelos argilominerais do grupo das esmectitas de acordo com o ensaio de capacidade de troca de cátions; esta informação configura-se como de grande importância para que se determine a necessidade de aditivação específica para perfuração da região contendo este tipo de formação geológica. Para o ensaio de Foster foi constatado que as 
amostras analisadas apresentaram inchamento alto para $o$ ensaio realizado sem a presença do inibidor, o que confirma a alta reatividade das amostras que contêm esmectita em sua composição, indicando que se faz necessário o estudo e avaliação do tipo de formação geológica para que a perfuração ocorra de modo seguro e evite-se que a mesma seja onerosa. Os ensaios de avaliação da eficiência dos inibidores químicos indicaram que a concentração que apresenta os melhores resultados para todos os inibidores estudados foi a de $20 \mathrm{~g} / 350 \mathrm{~mL}$ de água e que o inibidor citrato de potássio apresentou-se como o de melhor desempenho; pode-se indicar também que inibidores isentos de cloro apresentaram resultados superiores no comparativo ao desempenho do inibidor contendo cloro em sua composição; este resultado indica um importante dado, pois o cloreto de potássio que se apresenta como o inibidor mais largamente utilizado na indústria de perfuração para aditivação de fluidos inibidos contém cloro em sua composição, o que traz malefícios ao meio ambiente; assim, pode-se indicar que os inibidores isentos (ambientamente corretos) de cloro apresentaram melhor desempenho no controle da expansão das amostras analisadas. É previsível que o presente trabalho vai ajudar a melhorar o conhecimento sobre os folhelhos reativos, bem como contribuir para melhor indicação dos fluidos a serem utilizados nas perfurações de modo a promover uma operação segura e adequada.

\section{REFERÊNCIAS}

[1] X. Shuixiang, J. Guancheng, C. Mian, Pet. Expl. Development 3 (2011) 378.

[2] G.C. Albano, F.P. Fagundes, I.G.M. da Silva, B.A.B.D. Araújo, R.C. Balaban, Anais do $6^{\circ}$ PDPETRO, Florianópolis, SC (2011).

[3] W. Dye, K. D'Augereau, N. Hansen, M. Otto, L. Shoults, R. Leaper, D. Clapper, T. Xiang, SPE Annual Technical Conference and Exhibition 21 SPE- 92367-PA, Houston, U.S.A. (2006) 23.

[4] J. Montilva, E. Oort, R. Brahim, J.P. Luzardo, M. McDonald, L. Quintero, B. Dye, J. Trenery, SPE Annual Technical Conference and Exhibition, SPE-110366, Anaheim, U.S.A. (2007).
[5] R.L. Anderson, I. Ratcliffe, H.C. Greenwell, P.A. Williams, S.P. Cliffe, V. Coveney, Earth-Sci. Rev. 98 (2010) 201.

[6] I. Ismail, A.P. Huang, J. Teknologi 50 (2009) 53.

[7] S.A.B. Fontoura, Rock Mechanics Rock Eng. 45 (2012) 1001.

[8] D.V. Lucena, F.R. Santana, L.V. Amorim, J.A. Barbosa, Anais do $6^{\circ}$ Congresso Brasileiro de Petróleo e Gás, Florianópolis, SC (2011).

[9] K. Suguio, Dicionário de geologia sedimentar e áreas afins, BDC União de Editoras S.A, S. Paulo, Brasil (1998) 1190.

[10] T.M. Al-bazali, S. Al-mudhi, M.E. Chenevert, J. Petroleum Sci. Techn. 29 (2011) 312.

[11] R.T.Cygan, J.A. Greathouse, H. Heinz, A.G. Kalinichev, J. Mater. Chem. 9 (2009) 2470.

[12] P. Stefan, Efeito dos sais de $\mathrm{Na}, \mathrm{K}, \mathrm{Ca}, \mathrm{Mg}, \mathrm{Ba}$ e Sr sobre as propriedades da lama (drilling mud) nas perfurações profundas de petróleo e sal-gema, $3^{\text {rd }}$ Ed., Livraria Regina LTDA, Sergipe (1956).

[13] E. Van Oort, J. Petroleum Sci. Eng. 38 (2003) 213.

[14] C. Rabe, J.O. Cherrez, $5^{\text {th }}$ Asian Rock Mechanics Symposium, Sapporo, Japan (2009) 37.

[15] D.V. Lucena, H.L. Lira. L.V. Amorim, Rev. Eletr. Mater. Processos 6 (2011) 109.

[16] K.S. Katti, D.R. Katti, Langmuir 22 (2006) 532.

[17] C. Rabe, S.A.B. Fontoura, "Efeito dos sais orgânicos nas propriedades físicoquímicas de folhelhos", $2^{\circ}$ Congresso Brasileiro de Petróleo e Gás, Rio de Janeiro, RJ (2003).

[18] H.C. Ferreira, T. Chen, A.R. Zandonadi, P. Souza Santos, Cerâmica 18 (1972) 333.

[19] P. Souza Santos, Ciência e tecnologia de argilas, $2^{\text {nd }}$ Ed., Editora Edgard Blucher Ltda, S. Paulo, Brasil (1992) 408.

[20] M.D. Foster, Am. Mineralogy 38 (1953) 994.

[21] H. Celik, App. Clay Sci. 50 (2010) 245.

[22] R.R. Menezes, L.F.A. Campos, H.S. Ferreira, L.N. Marques, G.A. Neves, H.C. Ferreira, Cerâmica 55 (2009) 349.

[23] D.V. Lucena, H.L. Lira, L.V. Amorim, Rev. Tecnologia Metalurgia, Mater. Mineração 10 (2013) 287.

(Rec. 29/08/2015, Rev. 04/12/2015, Ac. 18/12/2015) 